\title{
Source process of the recurrent Tokachi-oki earthquake on September 26, 2003, inferred from teleseismic body waves
}

\author{
Yoshiko Yamanaka and Masayuki Kikuchi \\ Earthquake Research Institute, University of Tokyo, Tokyo 113-0032, Japan \\ (Received October 10, 2003; Revised December 25, 2003; Accepted December 25, 2003)
}

\begin{abstract}
On September 26, 2003, a large earthquake with a magnitude of 8.0 occurred along the Kuril trench off Tokachi, Hokkaido, Japan. We investigated the source process by using teleseismic $P$ - and $S H$-wave data. The main source parameters are as follows: the seismic moment $1.0 \times 10^{21} \mathrm{Nm}(M w=8.0)$; (strike, dip, rake $)=\left(230^{\circ}, 20^{\circ}, 109^{\circ}\right)$; the depth of initial break point $25 \mathrm{~km}$; source duration $40 \mathrm{sec}$; and the maximum slip $5.8 \mathrm{~m}$. We estimated the fault area to be $90 \times 70 \mathrm{~km}^{2}$, the average slip $2.6 \mathrm{~m}$, and the stress drop $5.0 \mathrm{MPa}$. This earthquake was an interplate earthquake associated with the subduction of the Pacific plate. The rupture propagated northward from a shallow to a deep region. In this area, a great earthquake (magnitude 8.2) occurred in 1952. We also made limited inversion of nearfield records of the 1952 event and found that the 2003 asperity was also ruptured in 1952. Our result suggests that the 2003 Tokachi-oki earthquake was a recurrent event of the 1952 Tokachi-oki earthquake.

Key words: Asperity, source process, recurrent event, Tokachi-oki earthquake, Kuril trench.
\end{abstract}

\section{Introduction}

A large earthquake occurred off Tokachi, Hokkaido, Japan, on September 26, 2003 (Fig. 1). This event was felt throughout the northeastern Japan. The maximum seismic intensity of 6 on the JMA scale was registered in the eastern Hokkaido. The hypocenter parameters determined by the Japan Meteorological Agency (JMA) were as follows: origin time $=$ 04:50:07.64 JST (Sep. 25, 19:50:07.64 UT), epicenter $=\left(41.780^{\circ} \mathrm{N}, 144.079^{\circ} \mathrm{E}\right)$, depth $=42 \mathrm{~km}$, and magnitude $=8.0$. In association with this earthquake, a tsunami was observed on the coast of Hokkaido and northeastern Honshu.

This earthquake occurred along the Kuril trench, where the Pacific Plate is subducted beneath Hokkaido at a rate of 8-9 cm/yr (e.g., DeMets, 1992). The epicenter was almost at the same location of the 1952 Tokachi-oki interplate earthquake (e.g., Hirata et al., 2003), as shown in Fig. 1. The average recurrence interval of great earthquakes along the Kuril trench is estimated as about 77 years (The Headquarters for Earthquake Research Promotion, 2003). Yamanaka and Kikuchi (2003) found that some asperities in northeastern Japan have repeatedly generated large earthquakes during the last 70 years, and pointed out that the location of such asperities is fixed in space. In this paper, we show that the 2003 earthquake was a re-rupture of an asperity of the 1952 Tokachi-oki earthquake.

\section{Point Source Solution}

We retrieved the broadband seismograms from Data Management Center of IRIS (Incorporated Research Institutions for Seismology) and chose the stations at epicentral distances

Copy right(C) The Society of Geomagnetism and Earth, Planetary and Space Sciences (SGEPSS); The Seismological Society of Japan; The Volcanological Society of Japan The Geodetic Society of Japan; The Japanese Society for Planetary Sciences. between $30^{\circ}$ and $100^{\circ}$ for $P$ waves and those between $40^{\circ}$ and $60^{\circ}$ for $S H$ waves, as shown in Fig. 2. We selected 21 vertical components of $P$-wave data and $4 S H$ data considering the quality of records and the azimuthal coverage of stations. The original records were converted into the ground displacement, and band-pass filtered between 0.004 and 1 $\mathrm{Hz}$.

We determined the focal mechanisms and the depth of a single point source using the inversion method of Kikuchi and Kanamori (1991). In order to calculate theoretical waveforms, we used a three-layer structure (Table 1), based on the result of Iwasaki et al. (1989), as a near-source structure. We assumed a trapezoidal source time function with duration of $25 \mathrm{sec}$.

The best waveform match was obtained for a depth of 45 $\mathrm{km}$. This depth may correspond to the centroid depth of the entire fault motion. The obtained focal mechanism is a reverse fault with a shallow dipping fault plane: (strike $\left(\Phi_{S}\right)$, $\operatorname{dip}(\delta)$, rake $(\lambda))=\left(215^{\circ}, 18^{\circ}, 96^{\circ}\right)$. The Harvard CMT solution $\left(252^{\circ}, 11^{\circ}, 136^{\circ}\right)$ and the USGS solution $\left(234^{\circ}\right.$, $7^{\circ}, 103^{\circ}$ ) also indicated that this earthquake was a thrust earthquake on the subducting plate interface.

\section{Source Process}

Next, we inverted the waveforms for a spatio-temporal distribution of slip on the fixed fault plane (Kikuchi and Kanamori, 2003). We considered a planar fault (strike $215^{\circ}$ and dip $18^{\circ}$ ) and placed $12 \times 8$ grid points with a spacing of $10 \mathrm{~km}$. The slip-rate function of each subfault was expanded in a series of 3 triangle functions with rise time of $2 \mathrm{sec}$. We assumed the maximum rupture front velocity of $2.7 \mathrm{~km} / \mathrm{sec}$ for a grid search.

We also determined the depth of the initial break by a grid search method varying the depth at every $1 \mathrm{~km}$. This revealed that $25 \mathrm{~km}$ was the best rupture starting point. This 

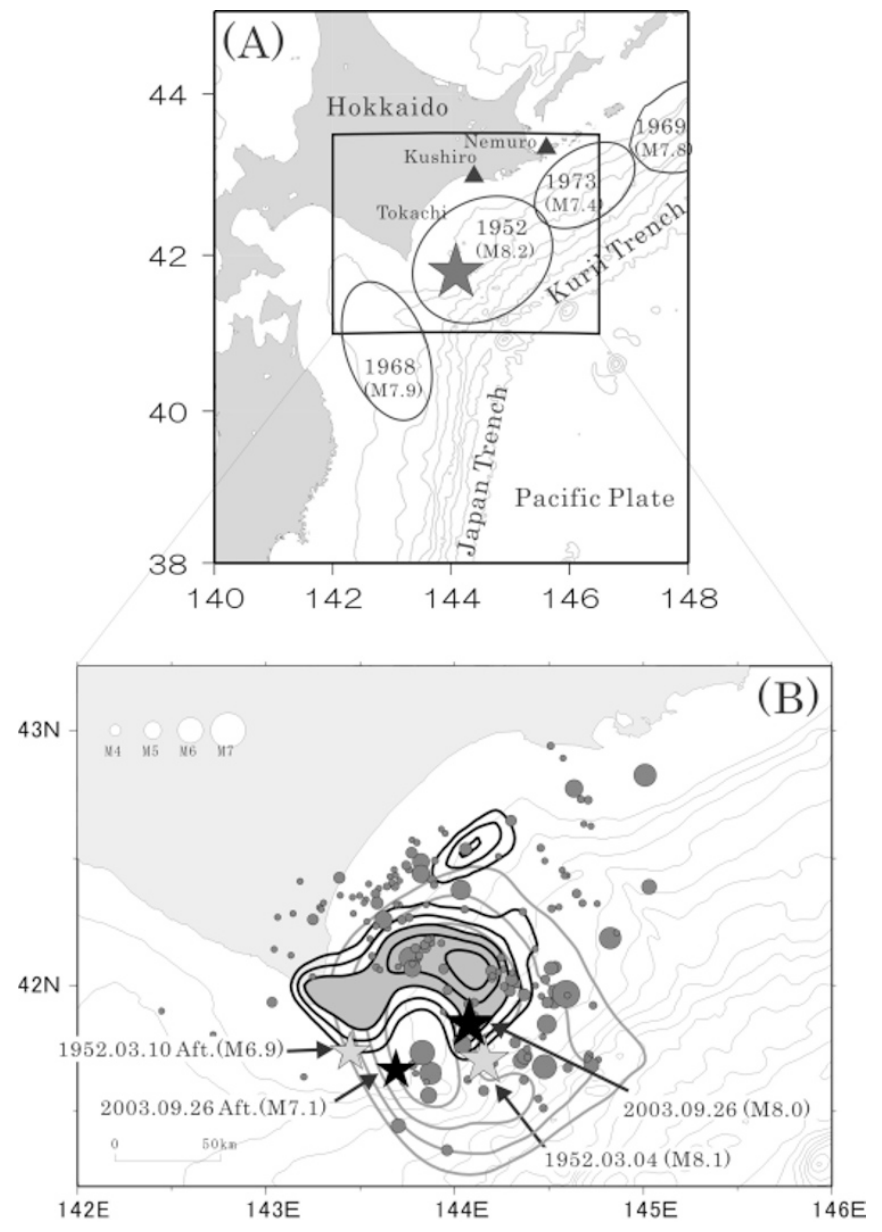

Fig. 1. (A) Location map for the epicenter of the 26 September 2003 Tokachi-oki earthquake (black star) and source regions of great interplate earthquake along the northern Japan Trench and the southern Kuril Trench. (B) Distribution of the main shock (large black star), the largest aftershock (small black star), and aftershocks within 10 hours after the main shock (gray circles) determined by Sakai and Hagiwara (personal communication). The black contours ( $1 \mathrm{~m}$ interval) show the fault slip distribution of the 2003 Tokachi-oki earthquake. The area with slip larger than a half of the maximum slip is defined as an asperity and hatched. Gray stars indicate the main shock and the largest aftershock of the 1952 Tokachi-oki earthquake. The gray contour $(0.3 \mathrm{~m}$ interval with the minimum of $1 \mathrm{~m})$ is the slip distribution of the 1952 earthquake as determined in this study.

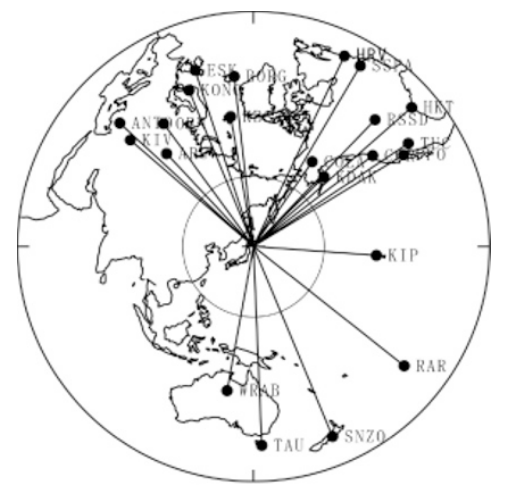

Fig. 2. Distribution of IRIS broadband seismograph stations used in this study. Map is drawn onto an equal distance projection. The inner and outer circles correspond to epicentral distances of $30^{\circ}$ and $100^{\circ}$, respectively.

depth corresponds to the interface of the subducting Pacific plate in this area (e.g., Katsumata et al., 2003). We also tried to obtain a better solution for the fault plane geometry by a trial-and-error method. This yields the best fit strike and dip of the fault plane as $230^{\circ}$ and $20^{\circ}$, respectively.
Table 1. Near-source structure used in this study.

\begin{tabular}{cccc}
\hline$V_{p}$ & $V_{s}$ & $\Delta$ & \multicolumn{1}{c}{$D$} \\
\hline 1.50 & 0.00 & 1.00 & 2.0 \\
6.50 & 3.74 & 2.87 & 20.0 \\
7.80 & 4.40 & 3.30 & -
\end{tabular}

$V_{p}, V_{s}=P$-wave and $S$-wave velocities $(\mathrm{km} / \mathrm{s})$, respectively; $\Delta=$ density $\left(10^{3} \mathrm{~kg} / \mathrm{m}^{3}\right) ; D=$ thickness $(\mathrm{km})$.

The final results are shown in Figs. 3(a) and 3(b). The total seismic moment $\left(M o=1.0 \times 10^{21} \mathrm{Nm}\right.$ or $\left.M w=8.0\right)$ obtained in this study is consistent with the USGS CMT solution $\left(M o=1.6 \times 10^{21} \mathrm{Nm}\right)$. The Harvard CMT solution $\left(M o=3.0 \times 10^{21} \mathrm{Nm}\right)$ is somewhat larger than other results. Figure 3(c) shows the spatio-temporal slip distribution on the shallow-dip fault plane. We assumed the shear modulus $\mu=60 \mathrm{GPa}$. A large slip is located about 20 to $50 \mathrm{~km}$ north of the initial rupture point. The rupture propagated northward to a deeper zone.

The final source parameters of the 2003 earthquake are summarized as follows: $\left(\Phi_{s}, \delta, \lambda\right)=\left(230^{\circ}, 20^{\circ}, 109^{\circ}\right)$; depth of initial break point $=25 \mathrm{~km}$; source duration $=40 \mathrm{sec}$; and 


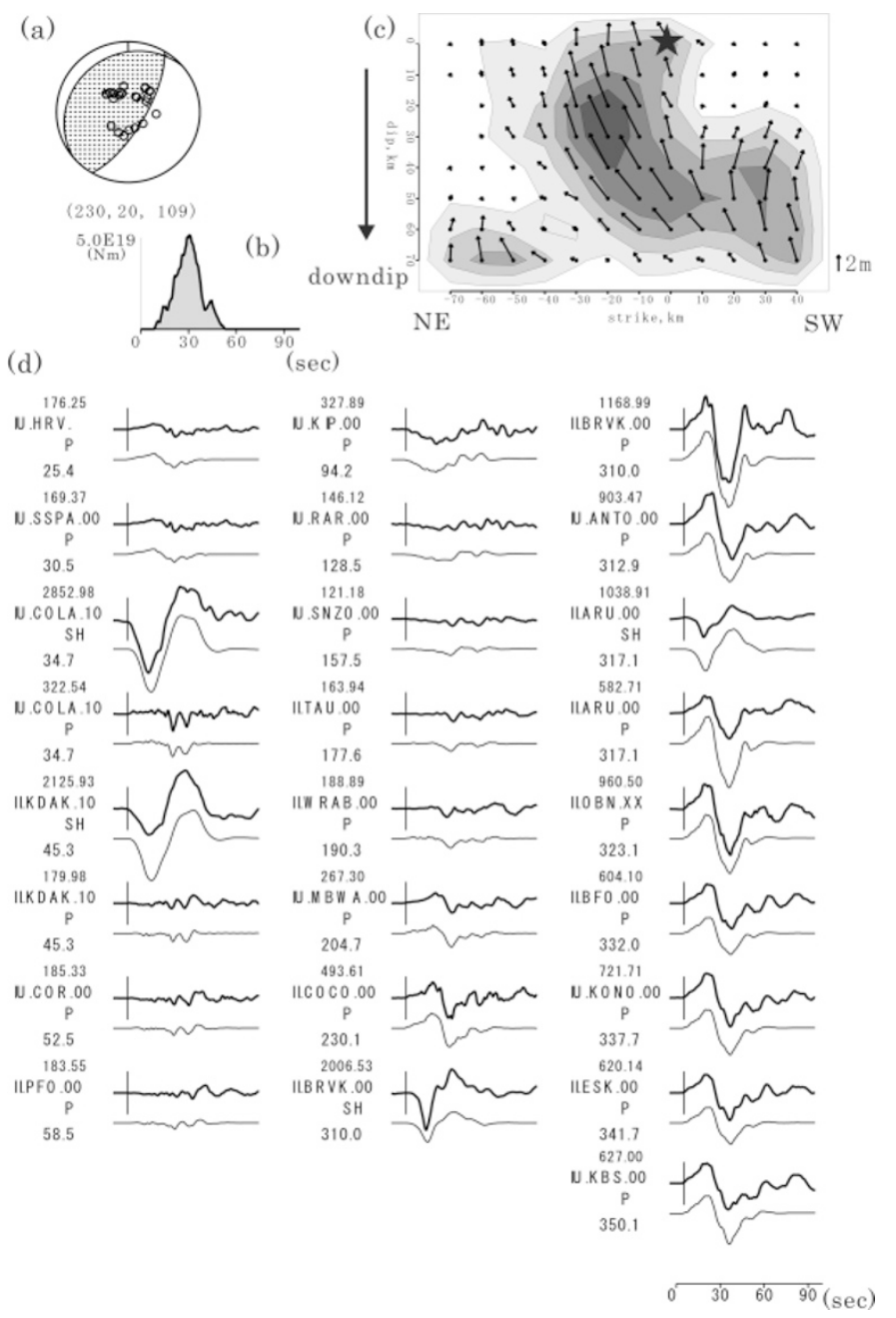

Fig. 3. Final solution of the 2003 Tokachi-oki earthquake. (a) Mechanism solution, (b) moment-rate function, (c) slip distribution on the fault plane (1.0 $\mathrm{m}$ interval), and (d) comparison of the observed (upper) and synthetic (lower) waveforms. The number above the station code is the peak-to-peak amplitude of the observed waveform (unit = micro-meter) and the number below the station code is the source-to-station azimuth.

maximum slip $=5.8 \mathrm{~m}$. The rupture propagated northward, and the fault area is roughly estimated to be about $S=90 \times$ $70 \mathrm{~km}^{2}$. Then we obtain the average slip $D=M o / \mu S=$ $2.6 \mathrm{~m}$, and average stress drop $\Delta \sigma=2.5 \mathrm{Mo} / \mathrm{S}^{1.5}=5.0$ $\mathrm{MPa}$. A comparison between the observed and synthetic waveforms is shown in Fig. 3(d).

\section{The 2003 Asperity}

Figure 1 shows the map view of the fault slip. We defined an asperity as the region where the seismic slip is larger than a half of the largest slip, as hatched in Fig. 1.

We also plotted the aftershocks that occurred during the 10 hours after the main shock, which were re-located by Earthquake Research Institute (Sakai and Hagiwara, personal communication) in Fig. 1. The asperity appears to be located in areas with fewer aftershocks. Similar characteristics were seen in earthquakes that occurred along the northern Japan Trench (Yamanaka and Kikuchi, 2003). Moreover, larger aftershocks seem to be concentrated on the trench side of the asperity, where little moment was released during the main shock.

About 90 minutes after the main shock, the largest aftershock with a magnitude of 7.1 occurred on the west side of the main shock, where no slip had been released by the main shock (see Fig. 1). This location is close to the epicenter of the largest aftershock (M 6.9) of the 1952 Tokachi-oki earthquake. An asperity with magnitude of around 7 may exist there.

\section{Comparison of the 1952 and the 2003 Earth- quakes}

We collected the strong motion seismographs of the 1952 earthquake from the JMA stations at Nemuro and Kushiro (Fig. 1). We digitized these waveform data recorded on smoked paper and applied the waveform inversion method developed by Kikuchi et al. (2003). The seismograms went off scale soon after the $S$-wave arrivals so we could not use the entire waveforms. We assumed the final fault plane $\left(\Phi_{s}\right.$, $\delta)=\left(230^{\circ}, 20^{\circ}\right)$ of the 2003 earthquake and determined the slip distribution on that plane.

The results are shown in Fig. 4. The obtained seismic moment was $5.8 \times 10^{20} \mathrm{Nm}(M w=7.8)$. The seismic moment and the maximum slip are quite insufficient, due to the fact that our inversion is limited to the initial part of the nearfield seismograms. The seismic moment obtained from tsunami waveforms is $1.87 \times 10^{21} \mathrm{Nm}$ (Hirata et al., 
(a)

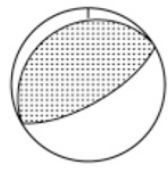

$(238,20,88)$

(b) $\mathrm{Mo}=5.8 \times 10^{20} \mathrm{Nm}$

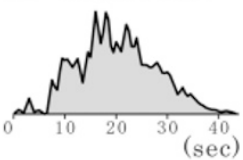

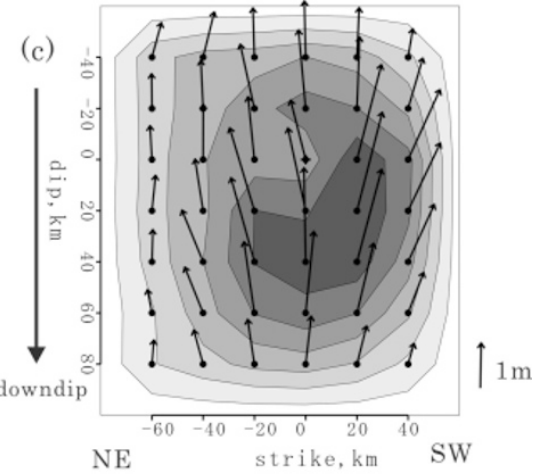

(d)
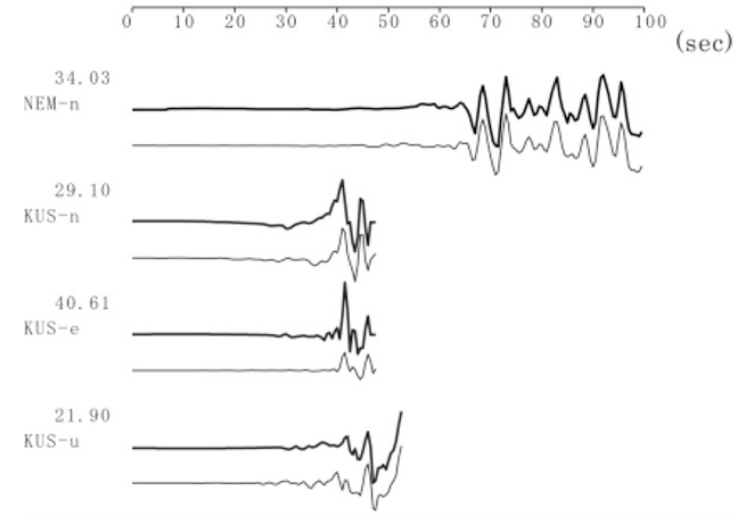

Fig. 4. Final solution of the 1952 Tokachi-oki earthquake. (a) Mechanism solution, (b) moment-rate function, (c) slip distribution on the fault plane ( $0.35 \mathrm{~m}$ interval), and (d) comparison of the observed (upper) and synthetic (lower) waveforms. The number above the station code is the peak-to-peak amplitude of the observed waveform (in $10^{-3} \mathrm{~m}$ ?).

2003), while our seismic moment is only less than $32 \%$ of it. However, the location of the asperity (Fig. 1) seems to match the area where few aftershocks occurred (Hamada and Suzuki, 2003). The asperity in 1952 and the asperity in 2003 appear to mostly overlap. That is, the 2003 earthquake is a recurrent event of the 1952 Tokachi-oki.

The 1952 earthquake might have involved other asperities. As stated above, we recovered only the initial part of rupture process. The 1952 slip distribution inferred from tsunami waveforms (Hirata et al., 2003) and difference in tsunami height distributions for the 1952 and 2003 events (Yuichiro Tanioka, personal communication) support such a possibility. Even if this is the case, the 2003 asperity coincides with at least one of the 1952 asperities.

We calculated the seismic coupling coefficient for this asperity of the 2003 Tokachi-oki earthquake. The interval between the 1952 and 2003 Tokachi-oki earthquakes is 51 years. The convergence rate of the subducting plate is about $8.5 \mathrm{~cm} / \mathrm{yr}$ and the asperity size is estimated to be about $S=$ $2900 \mathrm{~km}^{2}$. Consequently, the cumulative slip is equivalent with seismic moment of $7.5 \times 10^{20} \mathrm{Nm}$. On the other hand, the seismic moment released in the 2003 asperity was about $6.7 \times 10^{20} \mathrm{Nm}$. Therefore, it can be said that the seismic coupling coefficient in the asperity is close to $100 \%$.

Acknowledgments. We would like to thank Shin'ichi Sakai and Hiroko Hagiwara, who kindly provided us the data on aftershocks of the 2003 Tokachi-oki earthquake. We also thank Dr. Kenji Satake for many useful comments. The second author, Prof. Masayuki Kikuchi passed away on October 18th.

\section{References}

DeMets, C. Oblique convergence and deformation along the Kuril and Japan trenched, J. Geophys. Res., 97, 17615-17625, 1992.

Hamada, N. and Y. Suzuki, Re-examination of focal area of the 1952 Tokachi-oki earthquake, Prog. Abstr. Seismol. Soc. Jpn., 2, A044, 2003 (in Japanese).

Hirata, K., E. Geist, K. Satake, Y. Tanioka, and S. Yamaki, Slip distribution of the 1952 Tokachi-oki earthquake (M 8.1) along the Kuril Trench deduced from tsunami waveform inversion, J. Geophys. Res., 108, 2196 , doi:10.1029/2002JB001976, 2003.

Iwasaki, T., H. Shiobara, A. Nishizawa, T. Kanazawa, K. Suyehiro, N. Hirata, T. Urabe, and H. Shimamura, A detailed subduction structure in the Kuril trench deduced from ocean bottom seismographic refraction studies, Tectonophys., 165, 315-336, 1989.

Japan Meteorological Agency, http://www.jma.go.jp/JMA_HP/jma/press/ 0309/30b/tunami.pdf, 2003 (in Japanese).

Katsumata, K., N. Wada, and M. Kasahara, Newly imaged shape of the deep seismic zone within the subducting Pacific plate beneath the Hokkaido corner, Japan-Kurile arc-arc junction, J. Geophys. Res, 2003 (in press).

Kikuchi, M. and H. Kanamori, Inversion of complex body waves-III, Bull. Seism. Soc. Am., 81, 2335-2350, 1991.

Kikuchi, M., M. Nakamura, and K. Yoshikawa, Source rupture processes of the 1944 Tonankai earthquake and the 1945 Mikawa earthquake derived from low-gain seismograms, Earth Planets Space, 55, 159-172, 2003.

Kikuchi, M. and H. Kanamori, Note on Teleseismic Body-Wave Inversion Program, http://www.eri.u-tokyo.ac.jp/ETAL/KIKUCHI/, 2003.

The Headquarters for Earthquake Research Promotion, http://www.jishin. go.jp/main/chousa/03mar_chishima/index.htm, 2003.

Yamanaka, Y. and M. Kikuchi, Asperity map along the subduction zone in northeastern Japan inferred from regional seismic data, J. Geophys. Res., 2003 (submitted).

Y. Yamanaka (e-mail: sanchu@eri.u-tokyo.ac.jp) and M. Kikuchi 